\title{
OPEN Author Correction: Bases of Bacterial Sodium Channel Selectivity Among Organic Cations
}

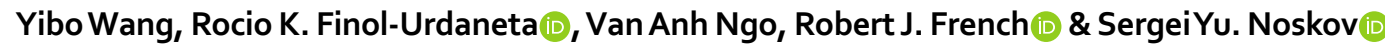

Correction to: Scientific Reports https://doi.org/10.1038/s41598-019-51605-y, published online 24 October 2019

In the original version of this Article, Yibo Wang and Rocio K. Finol-Urdaneta were omitted as equally contributing authors.

Furthermore, the Acknowledgments section in this Article was incomplete.

"This work was supported by grants from the Natural Sciences and Engineering Research Council (Canada) to S.Y.N. (NSERC RGPIN-315019) and the Alberta Innovates Technical Futures Strategic Chair in (Bio)Molecular Simulations. V.A.N. was financially supported by Postdoctoral Fellowships (AIHS and CIHR) during 2015-2018, and by LANL Director's Fellowship during 2018-2021 (V.A.N.). The classification number for this publication issued by LANL is LA-UR-19-29893. The experiments and simulations reported here also featured in the doctoral thesis of Y.W. https://prism.ucalgary.ca/handle/11023/3077. All of the computations were performed on the West-Grid/ Compute Canada facilities, and the University of Calgary TNK and GlaDos clusters acquired with direct support by the Canada Foundation for Innovation and NSERC RTI awards."

now reads:

"This work was supported by grants from the Natural Sciences and Engineering Research Council (Canada) to S.Y.N. (NSERC RGPIN-315019), and to R.J.F. (NSERC RGPIN-418658) and the Alberta Innovates Technical Futures Strategic Chair in (Bio)Molecular Simulations to S.Y.N. V.A.N. was financially supported by Postdoctoral Fellowships (AIHS and CIHR) during 2015-2018, and by LANL Director's Fellowship during 2018-2021 (V.A.N.). The classification number for this publication issued by LANL is LA-UR-19-29893. The experiments and simulations reported here also featured in the doctoral thesis of Y.W. https://prism.ucalgary.ca/handle/11023/3077. All of the computations were performed on the West-Grid/ Compute Canada facilities, and the University of Calgary TNK and GlaDos clusters acquired with direct support by the Canada Foundation for Innovation and NSERC RTI awards. Preliminary experiments by Ahmed Al-Sabi suggested the interesting difference in permeation of ammonium and hydrazinium through wild-type NaChBac, and its mutant, E191D."

This has now been corrected in the HTML and PDF versions of the Article.

Open Access This article is licensed under a Creative Commons Attribution 4.0 International License, which permits use, sharing, adaptation, distribution and reproduction in any medium or format, as long as you give appropriate credit to the original author(s) and the source, provide a link to the Creative Commons license, and indicate if changes were made. The images or other third party material in this article are included in the article's Creative Commons license, unless indicated otherwise in a credit line to the material. If material is not included in the article's Creative Commons license and your intended use is not permitted by statutory regulation or exceeds the permitted use, you will need to obtain permission directly from the copyright holder. To view a copy of this license, visit http://creativecommons.org/licenses/by/4.0/.

(C) The Author(s) 2019 